\title{
Soil desiccation cracks as a suction-contraction process
}

\author{
J. A. CORDERO*, G. USECHE*, P. C. PRAT*, A. LEDESMA* and J. C. SANTAMARINA $\dagger$
}

\begin{abstract}
Recent macro- and particle-scale advances in unsaturated soil behaviour have led to an enhanced understanding of the effects of moisture changes on soil response. This research examines desiccation cracks as a suction-contraction-coupled process using sand-clay mixtures. Suctionmoisture measurements highlight the role of fines on suction potential even at low fines content; on the other hand, oedometer tests exhibit a marked transition from sand-controlled to clay-controlled compressibility. Time-lapse photography of desiccation tests in flat trays show the onset of crack initiation and the subsequent evolution in horizontal strains; concurrent gravimetric water content measurements relate crack nucleation to suction at air entry. Suction and compressibility increase with the soil-specific surface and have a compounded effect on desiccation-driven lateral contraction. Both layer thickness and its lateral extent affect the development of desiccation cracks. The recently proposed revised soil classification system properly anticipates the transitions in compressibility and capillary phenomena observed in this study (between 15 and 35\% fines content).
\end{abstract}

KEYWORDS: clays; compressibility; sands; suction

ICE Publishing: all rights reserved

\section{INTRODUCTION}

Soil desiccation is central to soil-atmosphere interaction. Eventually, desiccation-induced shrinkage may lead to the typical polygonal network of cracks that have been observed at different scales (Corte \& Higashi, 1964; Hueckel et al., 2014). Soil properties, environmental characteristics and mechanical boundary conditions influence the evolution of desiccation cracks and patterns (Shokri et al., 2015).

Desiccation cracks alter the thermal, hydraulic and mechanical properties of soils (Vallejo, 2009). Crack formation is most relevant in the context of mine waste (Morris et al., 1992; Rodríguez et al., 2007), landfill liners, slope degradation, embankments, shallow foundations (Lozada et al., 2015), roads, agricultural lands (Sinnathamby et al., 2014), and even of the Martian landscape (El-Maarry et al., 2012).

Fundamentally, desiccation cracks are about changes in effective stress and volume contraction at the macroscale, and interparticle skeletal and capillary forces and grain displacements at the microscale. Desiccation cracks in soils are part of an extended family of open-mode discontinuities that include hydraulic fracturing, gas-driven fractures, ice or hydrate lenses, and even root growth (Shin \& Santamarina, 2011a; see also Wei et al., 2016). In fact, mechanical analysis - either at the particle level or in terms of effective stresses - is common to all of these discontinuities once differences between miscible fluids and immiscible invading fluids are recognised (Shin \& Santamarina, 2010).

Several experimental studies that have investigated the onset and propagation of desiccation cracks in soils (Scherer, 1990; Weinberger, 1999; Thusyanthan et al., 2007; Tang et al., 2011a; Cordero et al., 2016), explored the implications of soilatmosphere interaction (Blight, 1997; Gens, 2010), and tested

Manuscript received 1 July 2017; first decision 17 August 2017; accepted 23 August 2017.

Published online at www.geotechniqueletters.com on 4 October 2017.

${ }^{*}$ Department of Civil and Environmental Engineering, UPC-BarcelonaTECH, Barcelona, Spain.

$\dagger$ King Abdullah University of Science and Technology (KAUST), Thuwal, Saudi Arabia. the consequences of drying/wetting cycles (Herrera et al., 2007; Tang et al., 2011b; Cordero et al., 2014).

Clay-rich soils are particularly susceptible to volume change and desiccation cracks, in part, due to their high suction potential (Towner, 1987; Konrad \& Ayad, 1997; Albrecht \& Benson, 2001; Costa et al., 2013). Yet, suction is not sufficient by itself: the tendency to volume contraction and deformation-controlled boundary conditions must be intimately involved in fracture formation. Within this framework, the authors investigate the formation of desiccation cracks in soils as a coupled suction-contraction process.

\section{CHARACTERISATION TESTS}

The experimental study centres on 11 sand-kaolinite mixtures prepared in the following kaolinite mass fractions: $F_{\mathrm{k}}=M_{\mathrm{k}} /\left(M_{\mathrm{k}}+M_{\mathrm{s}}\right): 0,5,10,15,20,25,30,40,60,80$ and $100 \%$. Table 1 summarises the individual material properties of the sand and kaolinite used in all mixtures. Experiments measured oedometric compressibility, suction against water content [soil water retention curves (SWRC)] and desiccation tests inside an environmental chamber at constant relative humidity $\mathrm{RH}$ and temperature $T$, for all mixtures. Characterisation tests are described next.

\section{Compressibility}

The 11 mixtures were tested in floating ring oedometers (internal diameter $=63.5 \mathrm{~mm}$ ) to determine their compressibility between 1 and $1707 \mathrm{kPa}$. The saturated mixtures were prepared near the liquid limit (similar to subsequent desiccation tests). Stress-strain trends in Fig. 1 highlight the increased compressibility of the more plastic mixtures with kaolinite content.

Compression and recompression indices measured in oedometric tests show three marked zones (Fig. 2): mixtures with sand-controlled stiffness, transitional mixtures and the kaolinite-controlled mixture compressibility.

Coarse sand grains form a stiff granular skeleton in mixtures with low $F_{\mathrm{k}} \leq 25 \%$ (refer to fabric sketches, Fig. 2). The mass fraction of kaolinite $F_{\mathrm{k}}$ compacted at 
Table 1. Index properties of sand and kaolinite

\begin{tabular}{l|l|l|l}
\hline \multicolumn{2}{l|}{ Silica sand (Jeddha, KSA) } & \multicolumn{2}{l}{ Kaolinite (Gordon, USA) } \\
\hline Size range & $76-420 \mu \mathrm{m}$ & $100 \%$ finer than & Sieve $\# 200$ \\
Specific gravity & $G_{\mathrm{s}}=2 \cdot 63$ & Specific gravity & $G_{\mathrm{s}}=2 \cdot 67$ \\
Maximum void ratio & $e_{\max }=0 \cdot 81$ & Specific surface & $S_{\mathrm{s}}=33 \mathrm{~m}^{2} / \mathrm{g}$ \\
Minimum void ratio & $e_{\min }=0 \cdot 45$ & Liquid limits* & W67 B52 K82 \\
Roundness & $0 \cdot 5$ & Plastic limit & 34 \\
Coefficient of uniformity & $C_{\mathrm{u}}=10$ & USCS & $\mathrm{CH}$ \\
& & RSCS $\dagger$ & $\mathrm{I}-\mathrm{I}$ \\
& & Compression line & $e_{1} \mathrm{kPa}=1 \cdot 6$ \\
\hline
\end{tabular}

*Liquid limits for $\mathrm{W}$ - water, $\mathrm{B}$ - brine and $\mathrm{K}$ - kerosene.

$\dagger$ I-I: intermediate plasticity and intermediate sensitivity to pore fluid chemistry. For the new fines classification refers to Jang \& Santamarina (2017).

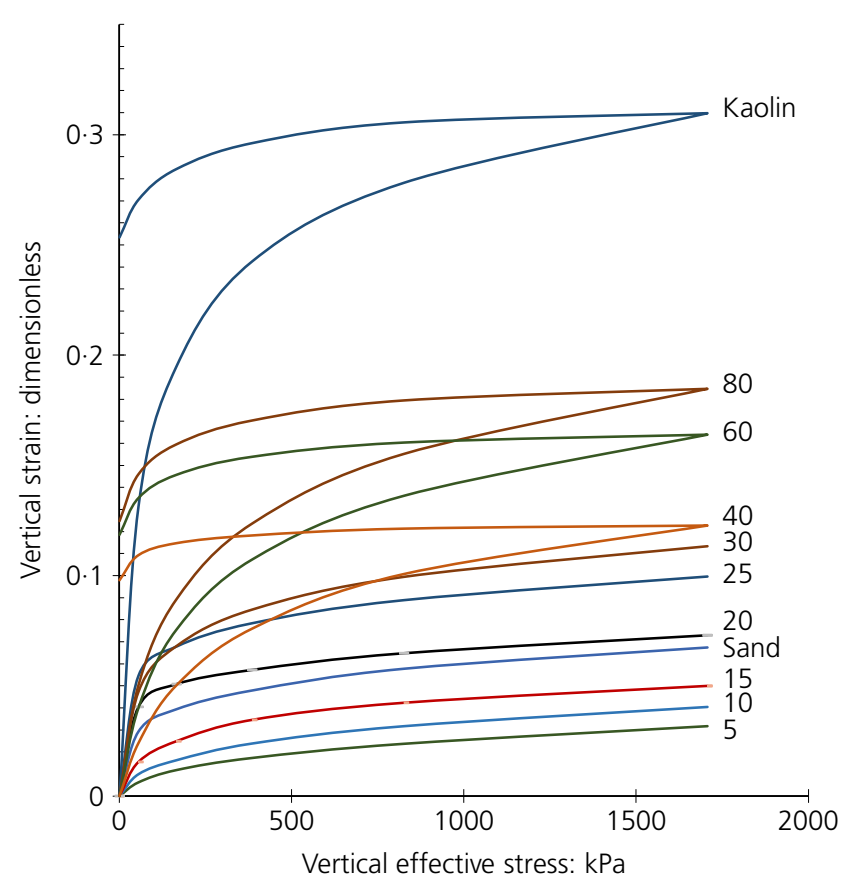

Fig. 1. Oedometric compression - all mixtures. For clarity, unloading curves plotted for kaolinite mass fraction: $F_{\mathrm{k}}=40$, 60,80 and $100 \%$. Note: initial void ratios vary according to the mixture liquid limit (refer to text)

void ratio $e_{\mathrm{k}}$ which is needed to fill the pores in sand skeleton packed at void ratio $e_{\mathrm{s}}$ estimated from a gravimetricvolumetric analysis (Zuo \& Baudet, 2015)

$$
F_{\mathrm{k}}=\frac{M_{\mathrm{k}}}{M_{\mathrm{k}}+M_{\mathrm{s}}} \approx \frac{e_{\mathrm{s}}}{1+e_{\mathrm{k}}+e_{\mathrm{s}}}
$$

where the approximation assumes that sand and kaolinite have similar specific gravities. For example, a kaolinite at void ratio $e_{\mathrm{k}}=0.9$ will fill the voids in packed medium-dense sand at $e_{\mathrm{s}}=0.70$ when the kaolinite mass fraction is $F_{\mathrm{k}}=27 \%$. This formulation combines with an extensive database of soil properties to define the soil classification boundaries in the revised soil classification system (RSCS) (Park \& Santamarina, 2017). The RSCS classification boundaries superimposed on Fig. 2 properly anticipate compressibility data gathered in this study.

There is a shift in the transition zone between the compression and recompression trends in Fig. 2: kaolinite consolidates and a sand skeleton forms during the consolidation of transitional mixtures. Once the skeleton forms, sands control the mixture stiffness during unloading and reloading paths, in agreement with equation (1).

\section{Suction}

The SWRC of all 11 mixtures are determined using a dew point hygrometer device (WP4C PotentiaMeter; Campbell et al., 2007). The gravimetric moisture and suction data were gathered during drying. Water potential readings started in wet specimens at a water content slightly lower than the liquid limit. Short drying times were used for the wet samples with suction values $<0 \cdot 1 \mathrm{MPa}$ in order to obtain several measurements. Thereafter, samples were dried in air for $\sim 1 \mathrm{~h}$ and equilibrated for $>24 \mathrm{~h}$ before every reading.

Figure 3 displays the total suction plotted against gravimetric water content for each mixture. A point near the air entry value (AEV) was obtained in all tests. Trends resemble the gap-graded grain size distribution curves as noted in previous studies (rotated by $90^{\circ}$, see Perera et al., 2005). The SWRC signatures exhibit marked differences among specimens; in particular, transitional mixtures exhibit a dual-porosity response (Stoicescu et al., 1996). Singleporosity, kaolinite-dominant signatures are observed for $F_{\mathrm{k}} \geq 25 \%$. The trend characteristics are compared in Fig. 4 .

- The suction near air entry and at almost-dry conditions $(w=2 \%)$ increase with kaolinite content even at very low $F_{\mathrm{k}}$ values (Fig. 4(a)). These trends highlight the controlling effect of small intergranular pores on suction.

- The gravimetric water loss between 100 and $1000 \mathrm{kPa}$ increases as the kaolinite fraction increases (Fig. 4(b)), in agreement with the compressibility trends in Fig. 2 and suction potential in Fig. 4(a). The least water loss takes place near $F_{\mathrm{k}} \approx 20 \%$ as intergranular pores in the sand skeleton are filled with kaolinite particles rather than water.

\section{DESICCATION TESTS}

\section{Specimen preparation and test procedure}

The homogeneously mixed dry mixtures were wetted until a smooth paste was obtained at a water content $\sim 30 \%$ higher than the liquid limit. Then, the pastes were evenly laid to fill flat trays $(300 \mathrm{~mm} \times 300 \mathrm{~mm} \times 20 \mathrm{~mm})$ to emphasise horizontal shrinkage and desiccation crack formation. Trays were kept in an environmental chamber at $\mathrm{RH}=40 \%$ and $T=35^{\circ} \mathrm{C}$. Weight measurements and photographic images taken at regular intervals document the evolution of the specimens.

\section{Gravimetric data}

The evaporation rate in terms of gravimetric water content $\Delta w \% / \Delta t \approx 4 \pm 0 \cdot 3$ was similar in all specimens for the first few hours. The arrows superimposed on evaporation trends in Fig. 5 mark the onset of crack formation. Specimens with low $F_{\mathrm{k}} \leq 15 \%$ did not develop cracks. 


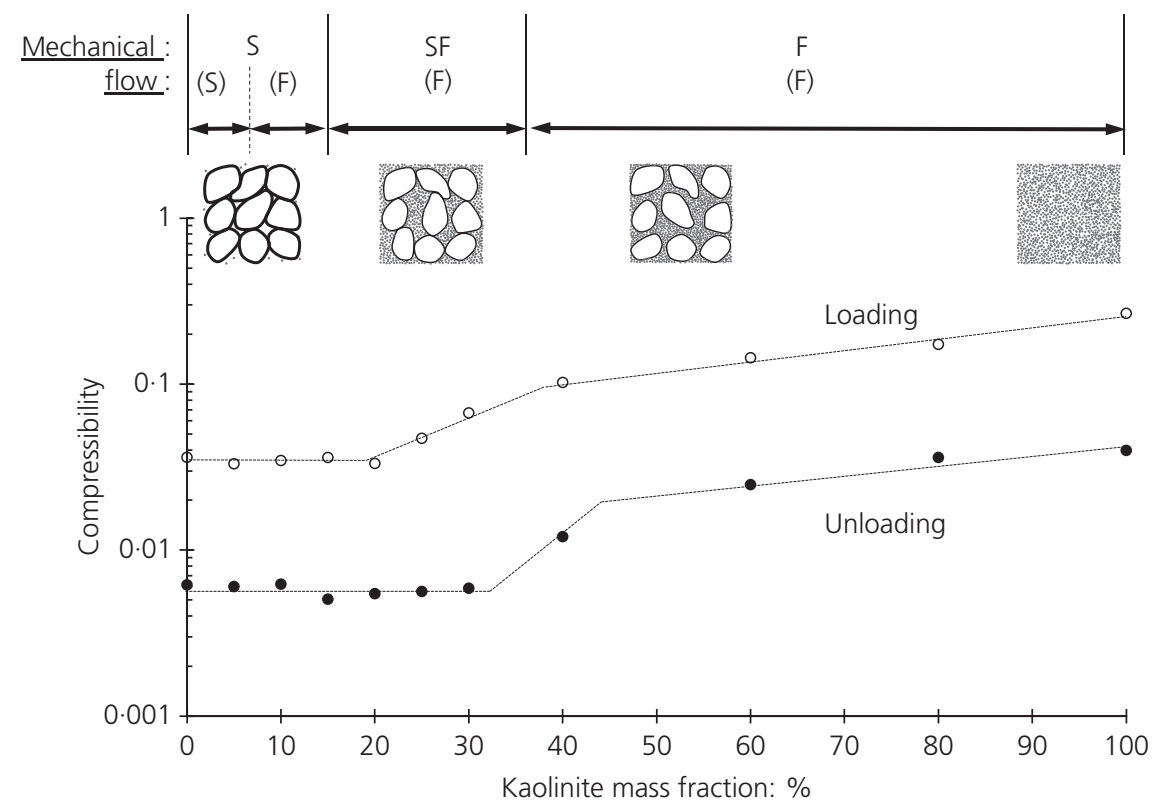

Fig. 2. Compressibility during loading and unloading against kaolinite mass fraction. Compressibility computed as $C=\Delta e / \log$ $\left[\left(\sigma_{0}^{\prime}+\Delta \sigma^{\prime}\right) / \sigma_{0}^{\prime}\right]$. The RSCS shown at the top of the figure recognises the fraction that controls the mechanical behaviour and the fraction that controls fluid flow (respectively, the first and second letter in parenthesis), refer to Park \& Santamarina (2017)
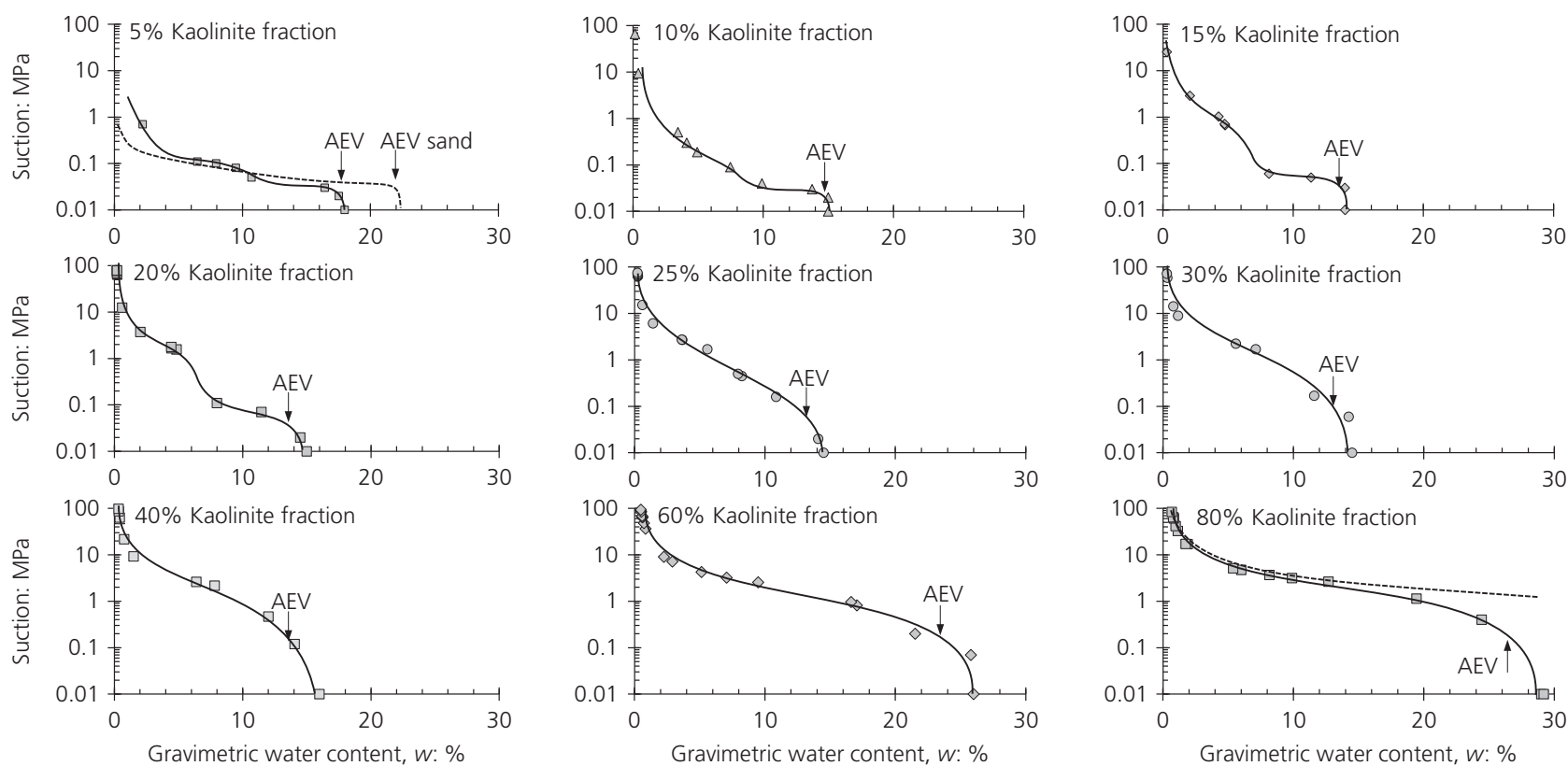

Fig. 3. Total suction against gravimetric water content. Note: $100 \%$ sand superimposed on $F_{\mathrm{k}}=5 \%$ kaolinite (dotted line); the $100 \%$ kaolinite SWRC trend is superimposed on $F_{\mathrm{k}}=80 \%$ (dotted line $-\mathrm{AEV}=0.3 \mathrm{MPa}$ )

The authors used the cone penetration method to determine the liquid limit $w_{\mathrm{L}}$ for all mixtures. The liquid limit of $100 \%$ sand is estimated as the water content in saturated sand at the maximum void ratio $e_{\max }$. Figure 6 compares the liquid limit $w_{\mathrm{L}}$, gravimetric water content at fracture initiation $w_{\text {frac }}$ and water content at air entry $w_{\mathrm{AE}}$ obtained from the water retention curves; the following trends are seen.

- The gravimetric water contents at fracture initiation $w_{\text {frac }}$ follow closely the AEVs $w_{\mathrm{AE}}$ obtained from the water retention curves. Both values are lower than the corresponding liquid limit $w_{\mathrm{L}}$ (note: as a corollary, soils are saturated at the liquid limit).

- Consequently, desiccation cracks form in saturated soft sediments when the immiscible air phase is suction driven to invade the water-saturated sediment (Shin \& Santamarina, 2011b).

- The liquid limit is not linear with the mass fraction of kaolinite, in general agreement with mixture data presented in Sivapullaiah \& Sridharan (1985).

However, the data in Fig. 6 show that the minimum liquid limit - determined with the cone method - takes place at $F_{\mathrm{k}} \approx 25 \%$. The higher liquid limits for sand-controlled mixtures point to the pore-filling role of kaolinite at low fines fraction $\left(F_{\mathrm{k}}<25 \%\right.$, refer to the fabric sketches in Fig. 2). Eventually, kaolinite controls the mixture plasticity for $F_{\mathrm{k}}>25 \%$.

Trends group mixtures into three zones: coarse-controlled with minimal volume contraction and undetected cracks, 


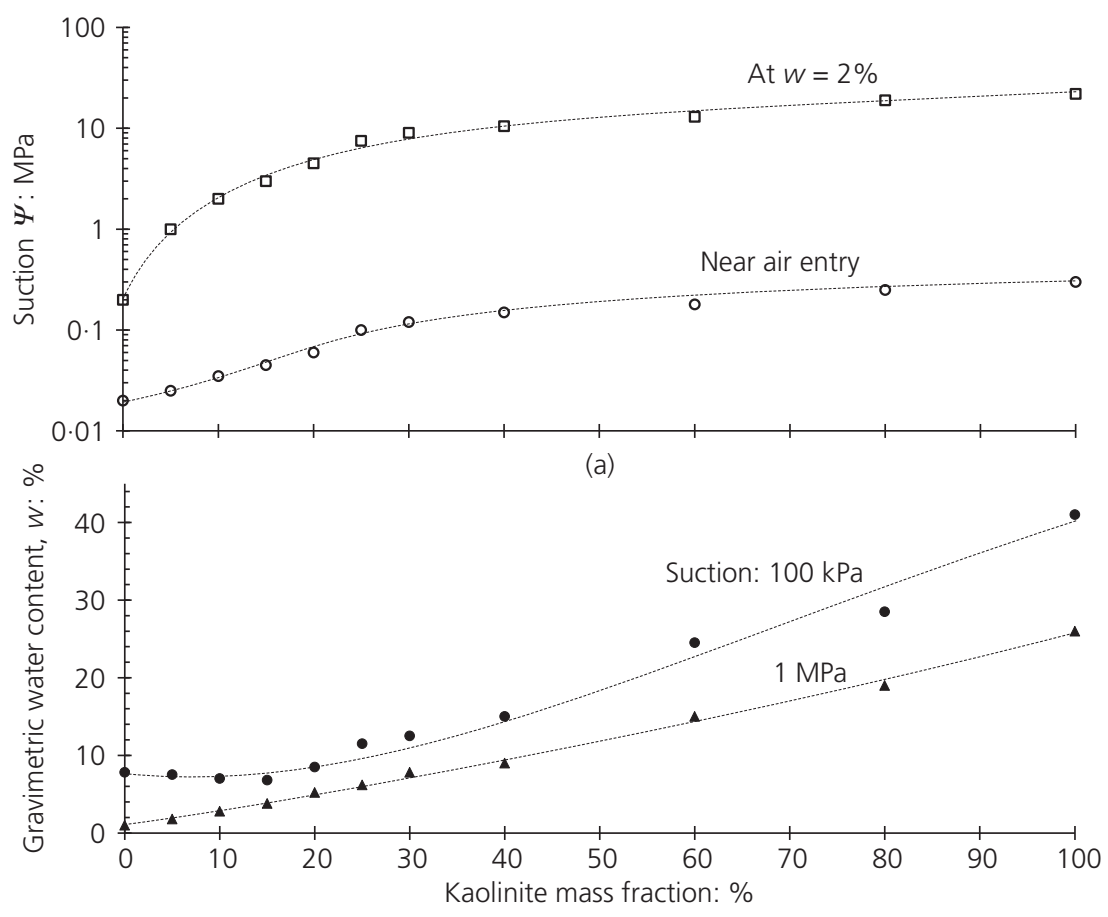

(b)

Fig. 4. Suction and gravimetric water content at selected stages of desiccation (from SWRCs) as a function of kaolinite mass fraction
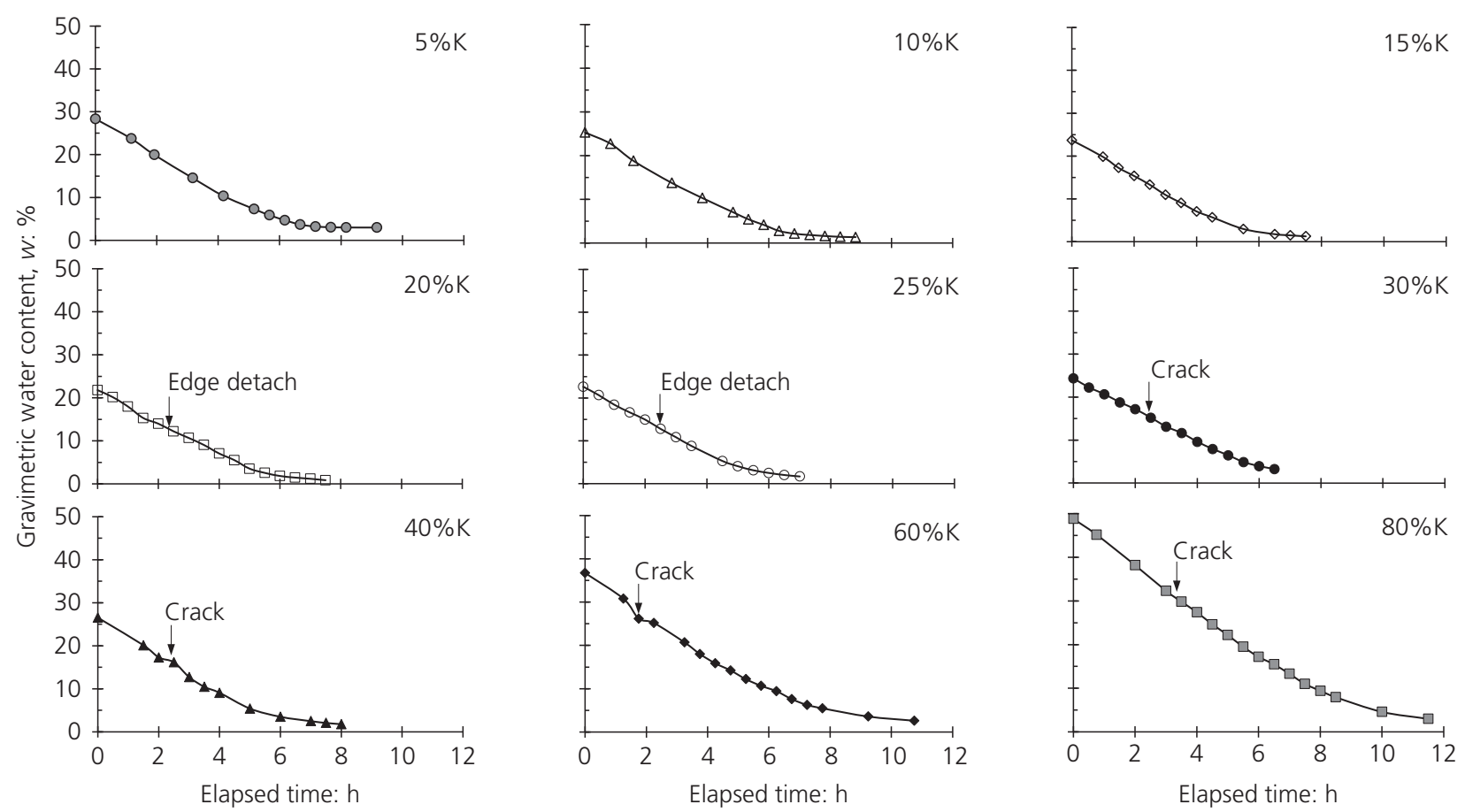

Fig. 5. Gravimetric water content against desiccation time. The onset of edge detachment and cracking is identified in each case

intermediate transitional mixtures and fines controlled with well-defined fracture patterns. Once again, the RSCS boundaries are in agreement with transitions in capillary phenomena that are summarised in Fig. 6.

\section{Desiccation and cracks}

Time-lapse photography and digital image analysis provided detailed spatial data to assess crack initiation and propagation (similar to the methodology used in Lu \& Kaya, 2013). Vertical contraction changes to lateral contraction at the onset of fracture formation (similar to observations in Shin \& Santamarina, 2011b). Edge separation/cracks appear in mixtures with kaolinite fractions $F_{\mathrm{k}}=20$ and $25 \%$; both edge and internal cracks form in all other mixtures with higher clay content.

Figure 7 presents thresholded photographs of all the specimens that experienced edge separation and internal cracks. Crack patterns exhibit the standard $T$ and $Y$ intersections that reflect the evolving effective stresses and formation history.

The crack intensity factor (CIF) relates the area of edge and internal cracks to the total area of the tray (Miller et al., 1998). 


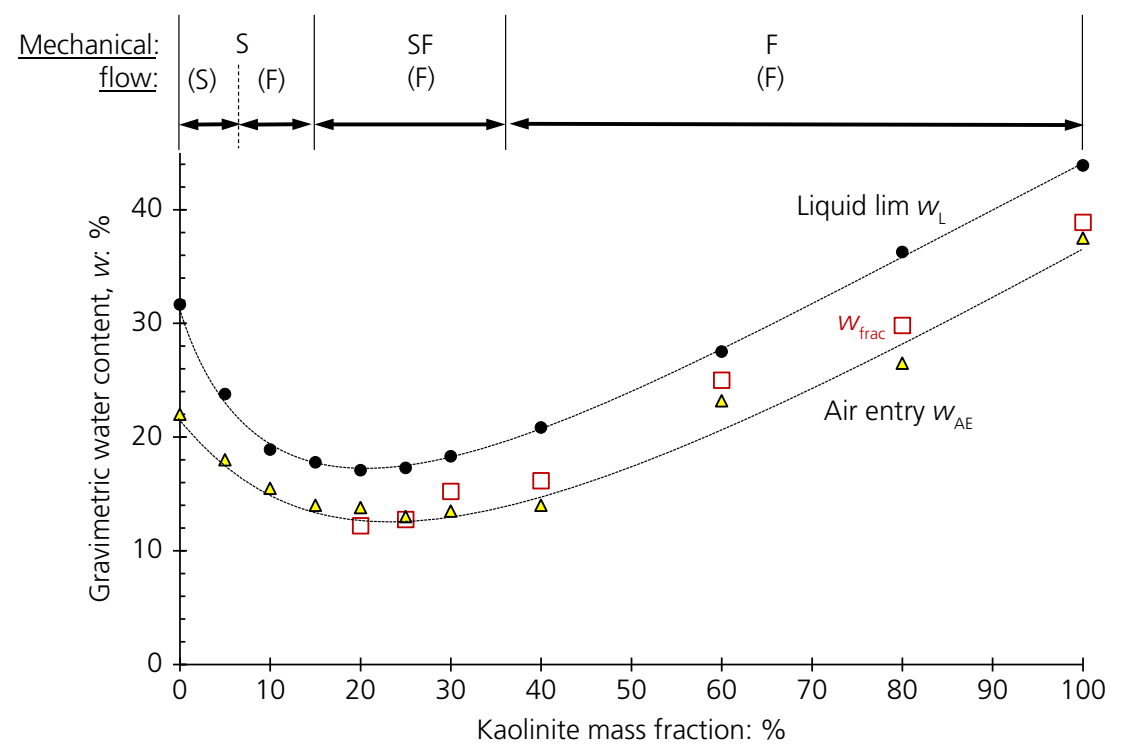

Fig. 6. Gravimetric water content at different stages of desiccation against kaolinite mass fraction. Values shown for liquid limit $w_{\mathrm{L}}$, at the onset of fracture formation $w_{\text {frac }}$ and at air entry $w_{\mathrm{AE}}$. The RSCS zones are shown at the top of the figure (refer Fig. 2)

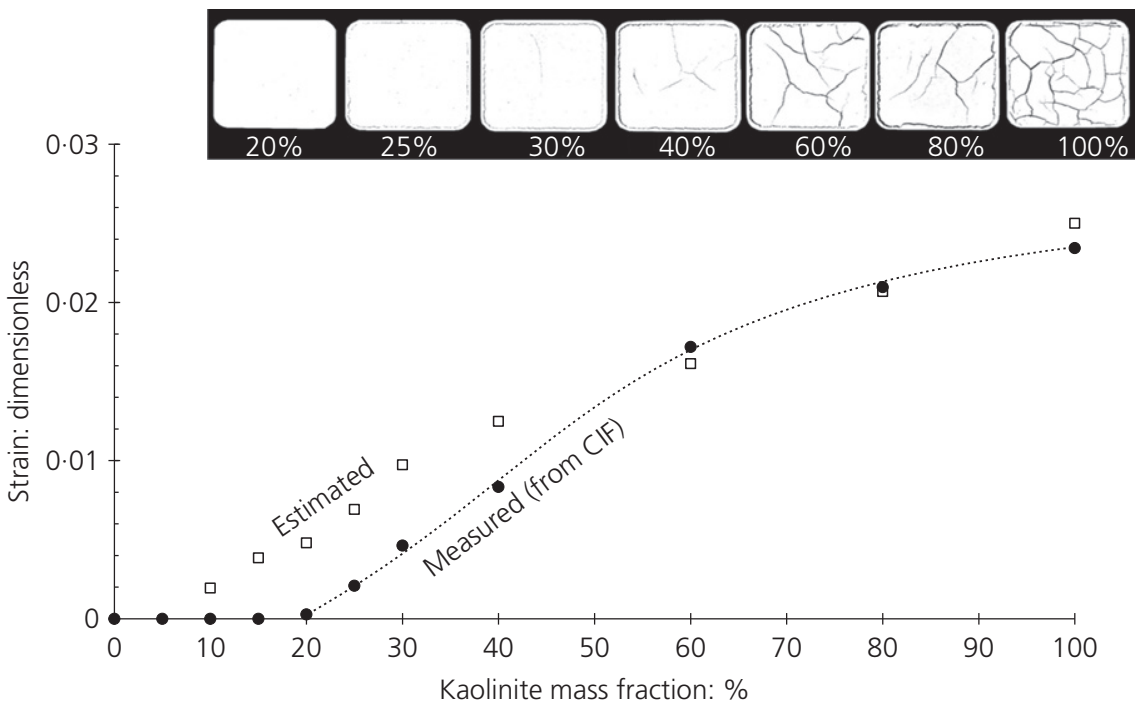

Fig. 7. Desiccation cracks in sand-kaolinite mixtures as a function of the kaolinite mass fraction. (a) Photographs captured at the end of drying. (b) The measured strain $\varepsilon_{x}=\mathrm{CIF} / 2$ and the strain estimated using compressibility and suction data for a Bishop parameter $\lambda=0.021$ (fitted for high kaolinite content mixtures)

$$
\mathrm{CIF}=\frac{\text { Area of cracks }}{\text { Total area }} \approx 2 \varepsilon_{x}
$$

The approximation for the linear contractile strain $\varepsilon_{x} \approx \mathrm{CIF} / 2$ applies to small strains. There is a pronounced increase in contractile strain when the kaolinite mass fraction exceeds $F_{\mathrm{k}} \geq 20 \%$ (Fig. 7).

\section{Suction-contraction}

A Bishop-like formulation allows for a first-order estimate of the strain the sediment would experience in the horizontal direction as the suction increases from $\Psi=\mathrm{AEV}$ (nearfracture initiation-Bishop's $\lambda_{\mathrm{AE}} \approx 1 \cdot 0$ ) to a value of suction $\psi_{2 \%}$ measured at near-dry conditions $w=2 \%$

$$
\varepsilon_{\mathrm{est}}=\frac{C_{C}}{1+e_{\mathrm{AE}}} \log \frac{\lambda_{2 \%} \psi_{2 \%}}{\psi_{\mathrm{AE}}}
$$

The transverse compressibility is in the order of $C_{c}$ values (Fig. 2), and the gravimetric water content at air entry defines the void ratio $e_{\mathrm{AE}}$. The measured $\varepsilon_{x}$ and estimated strains $\varepsilon_{\text {est }}$ match for mixtures with high kaolinite content when the Bishop parameter is $\lambda_{2 \%} \approx 0.021$ for near-dry conditions $w=2 \%$ (Fig. $7-\lambda_{2 \%}$ is assumed constant for all mixtures). The low $\lambda_{2} \%$ value confirms a high degree of air invasion into sediment blocks between desiccation cracks. This analysis would suggest that early air invasion results in low $\lambda$ values and diminishes the effect of suction on contraction.

Base friction hinders free contraction and promotes more closely spaced desiccation cracks. In fact, preliminary experiments that involved mixtures placed on Teflon-coated trays resulted in edge separation in all mixtures (also note that the predicted strains are larger than the measured strains $\varepsilon_{\text {est }}>\varepsilon_{x}$ for all specimens with a low kaolinite content in Fig. 7). In natural systems, the layer thickness and its lateral extent affect the development of desiccation cracks. For example, 
giant desiccation cracks have been observed in large valleys filled with sandy sediments with some fines - that is, stiff skeleton with low $F_{\mathrm{k}}$ values. Small-scale laboratory experiments are inherently unable to reproduce desiccation crack formation in such sediments.

Analytical and empirical equations predict that both suction $\psi$ and compressibility $C_{c}$ increase with specific surface $S_{\mathrm{s}}$.

From Laplace's equation - at air entry

$$
\psi=\frac{2 T_{\mathrm{s}} \rho}{e} S_{\mathrm{s}}
$$

From $C_{c}-w_{\mathrm{L}}$ and $w_{\mathrm{L}}-S_{\mathrm{s}}$ correlations

$$
C_{c}=0 \cdot 02+0 \cdot 005 S_{\mathrm{s}}
$$

where $T_{\mathrm{s}}$ is the surface tension, $\rho$ is the mineral mass density and the pore radius is estimated as $e /\left(\rho S_{\mathrm{s}}\right)$ for parallel platy particles. Therefore, soils that can mobilise higher suction tend to be more compressible; this global trend prevails even in gap-graded mixtures such as those tested in this study. Suction and compressibility combine to cause the large horizontal strains associated with desiccation cracks (equation (3)).

\section{CONCLUSIONS}

Saturated soft sediments contract and stiffen as water evaporates. Eventually, suction causes air invasion. The gravimetric water content at air entry in SWRCs is about the same as the water content at fracture initiation in desiccation tests; both gravimetric water contents are lower than the liquid limit. Therefore, desiccation cracks open-mode discontinuities driven by air invasion into soft sediments.

Desiccation crack formation is a coupled suctioncontraction process. Overall, suction and compressibility increase with the soil-specific surface and have a compounded effect on the development of desiccation cracks. In gap-graded sand-clay mixtures, compressibility trends define three marked zones: sand-controlled, transitional and clay-controlled mixture compressibility. However, suction at selected saturation conditions increases with clay content even at very low clay fractions.

Boundary conditions are intimately involved in fracture formation. Both the layer thickness and its lateral extent affect the development of desiccation cracks. Small-scale laboratory experiments are inherently unable to reproduce field-observed desiccation cracks in clayey sands with sand-controlled skeletal stiffness, even when the clay fraction can sustain high suction.

The recently proposed RSCS properly anticipates compressibility trends and the transitions in capillary phenomena observed in this study - that is, between 15 and 35\% fines content for sand-kaolinite mixtures.

\section{ACKNOWLEDGEMENTS}

This research was funded by the KAUST endowment and by a UPC award from the Spanish Ministry of Economy and Competitiveness (grants BIA2012-36498 and BES-2013-062706). G. E. Abelskamp edited the earlier versions of the manuscript. Anonymous reviewers contributed insightful comments and references.

\section{REFERENCES}

Albrecht, B. \& Benson, C. (2001). Effect of desiccation on compacted natural clays. J. Geotech. Geoenviron. Engng 127, No. 1, $67-75$.
Blight, G. (1997). Interactions between the atmosphere and the Earth. Géotechnique 47, No. 4, 713-767, http://dx.doi.org/ 10.1680/geot.1997.47.4.713.

Campbell, G. S., Smith, D. M. \& Teare, B. L. (2007). Application of a dew point method to obtain the soil water characteristic. In Springer proceedings in physics: experimental unsaturated soil mechanics (ed. T. Schanz), vol. 112, pp. 71-77. Berlin, Heidelberg: Springer-Verlag.

Cordero, J., Cuadrado, A., Ledesma, A. \& Prat, P. (2014). Patterns of cracking in soils due to drying and wetting cycles. In Unsaturated soils: research \& applications (eds N. Khalili, A. Russell and A. Khoshghalb), pp. 381-387. Sydney, Australia: CRC Press.

Cordero, J., Cuadrado, A., Prat, P. \& Ledesma, A. (2016). Description of a field test involving cracking in a drying soil. In Proceedings of the 3rd European conference on unsaturated soils. E3S web of conferences (eds P. Delage, Y.-J. Cui, S. Ghabezloo, J.-M. Pereira and A.-M. Tang), vol. 9, pp. 1-6. Paris, France: EDP Sciences, 12005.

Corte, A. \& Higashi, A. (1964). Experimental research on desiccation cracks in soils, U.S. Army Materiel Command Cold Regions Research \& Engineering Laboratory, Hanover, New Hampshire, CRREL Research Report 66.

Costa, S., Kodikara, J. \& Shannon, B. (2013). Salient factors controlling desiccation cracking of clay in laboratory experiments. Géotechnique 63, No. 1, 18-29, http://dx.doi.org/ 10.1680/geot.9.P.105.

El-Maarry, M. R., Kodikara, J., Wijessoriya, S., Markiewicz, W. J. \& Thomas, N. (2012). Desiccation mechanism for formation of giant polygons on Earth and intermediate-sized polygons on Mars: results from a pre-fracture model. Earth Planet. Sci. Lett. 323-324, 19-26, http://dx.doi.org/10.1016/j.epsl.2012. 01.016 .

Gens, A. (2010). Soil-environment interactions in geotechnical engineering. Géotechnique 60, No. 1, 3-74, http://dx.doi.org/ 10.1680/geot.9.P.109.

Herrera, M. C., Lizcano, A. \& Santamarina, J. C. (2007). Colombian volcanic ash soils. In Proceedings of the second international workshop on characterization and engineering properties of natural soils Singapore (eds T. S. Tan, K. K. Phoon, D. W. Hight and S. Leroueil), vol. 3, pp. 2385-2409. London, UK: Taylor \& Francis.

Hueckel, T., Mielniczuk, B., El Youssoufi, M., Hu, L. \& Laloui, L. (2014). A three-scale cracking criterion for drying soils. Acta Geophys. 62, No. 5, 1049-1059.

Jang, J. \& Santamarina, J. C. (2017). Closure to fines classification based on sensitivity to pore-fluid chemistry. J. Geotech. Geoenviron. Engng 143, No. 7, pp. 1-5, 07017013.

Konrad, J. M. \& Ayad, R. (1997). An idealized framework for the analysis of cohesive soils undergoing desiccation. Can. Geotech. J. 34, No. 4, 477-488.

Lozada, C., Caicedo, B. \& Thorel, L. (2015). Effects of cracks and desiccation on the bearing capacity of soil deposits. Géotech. Lett. 5, No. 3, 112-117, http://dx.doi.org/10.1680/jgele. 15.00021 .

Lu, N. \& Kaya, M. (2013). A drying cake method for measuring suction-stress characteristic curve, soil-water-retention curve, and hydraulic conductivity function. Geotech. Test. J. 36, No. 1, $1-19$.

Miller, C. J., Mi, H. \& Yesiller, N. (1998). Experimental analysis of desiccation crack propagation in clay liners. J. Am. Water Resour. Assoc. 34, No. 3, 677-687.

Morris, P. H., Graham, J. \& Williams, D. J. (1992). Cracking in drying soils. Can. Geotech. J. 29, No. 2, 263-277.

Park, J. \& Santamarina, J. C. (2017). Revised soil classification system for coarse-fine mixtures. J. Geotech. Geoenviron. Engng 143, No. 8, pp. 1-13, 04017039.

Perera, Y., Zapata, C., Houston, W. \& Houston, S. (2005). Prediction of the soil-water characteristic curve based on grain-size-distribution and index properties. In Geo-frontiers, Austin, TX, USA (eds W. S. Charles, T. Erol and T. Laith), Geotechnical Special Publication 130, pp. 49-60. Reston, VA, USA: American Society of Civil Engineers.

Rodríguez, R., Sánchez, M., Ledesma, A. \& Lloret, A. (2007). Experimental and numerical analysis of desiccation of a mining waste. Can. Geotech. J. 44, No. 6, 644-658. 
Scherer, G. W. (1990). Theory of drying. J. Am. Ceram. Soc. 73 , No. 1, 3-14.

Shin, H. \& Santamarina, J. C. (2010). Fluid-driven fractures in uncemented sediments: underlying particle-level processes. Earth Planet. Sci. Lett. vol. 299, No. 1-2, pp. 180-189, http:// dx.doi.org/10.1016/j.eps1.2010.08.033.

Shin, H. \& Santamarina, J. C. (2011a). Open-mode discontinuities in soils. Géotech. Lett. 1, No. 4, 95-99, http://dx.doi.org/10.1680/ geolett.11.00014.

Shin, H. \& Santamarina, J. C. (2011b). Desiccation cracks in saturated fine-grained soils: particle-level phenomena and effective-stress analysis. Géotechnique 61, No. 11, 961-972, http://dx.doi.org/10.1680/geot.8.P.012

Shokri, N., Zhou, P. \& Keshmiri, A. (2015). Patterns of desiccation cracks in saline bentonite layers. Transp. Porous Media 110 No. 2, 333-344.

Sinnathamby, G., Pasky, A., Phillips, D. H. H. \& Sivakumar, V. (2014). Landfill cap models under simulated climate change precipitation: impacts of cracks and root growth. Géotechnique 64, No. 2, 95-107, http://dx.doi.org/10.1680/geot.12.P.140.

Sivapullaiah, P. V. \& Sridharan, A. (1985). Liquid limit of soil mixtures. Geotech. Test. J. 8, No. 3, 111-116.

Stoicescu, J. F., Haug, M. D. \& Fredlund, D. G. (1996). The soil-water characteristics and pore-size distribution of a sandbentonite mixture. In Proceedings of the 49th Canadian geotechnical conference, St. John's, NL, Canada, vol. 2, pp. 721-728. Richmond, BC, Canada: Canadian Geotechnical Society.
Tang, C. S., Shi, B., Liu, C., Gao, L. \& Inyang, H. I. (2011a). Experimental investigation of the desiccation cracking behavior of soil layers during drying. J. Mater. Civil Engng 23, No. 6, 873-878.

Tang, C. S., Cui, Y. J., Shi, B., Tang, A. M. \& Liu, C. (2011b). Desiccation and cracking behaviour of clay layer from slurry state under wetting-drying cycles. Geoderma 166, No. 1, 111-118.

Thusyanthan, N. I., Take, W. A., Madabhushi, S. P. G. \& Bolton, M. D. (2007). Crack initiation in clay observed in beam bending. Géotechnique 57, No. 7, 581-594, http://dx.doi. org/10.1680/geot.2007.57.7.581.

Towner, G. D. (1987). The mechanics of cracking of drying clay. J. Agric. Engng Res. 36, No. 2, 115-124.

Vallejo, L. E. (2009). Fractal analysis of temperature-induced cracking in clays and rocks. Géotechnique 59, No. 3, 283-286, http://dx.doi.org/10.1680/geot.2009.59.3.283.

Wei, X., Hattab, M., Bompard, P. \& Fleureau, J. M. (2016) Highlighting some mechanisms of crack formation and propagation in clays on drying path. Géotechnique 66, No. 4, 287-300, http://dx.doi.org/10.1680/jgeot.14.P.227.

Weinberger, R. (1999). Initiation and growth of cracks during desiccation of stratified muddy sediments. J. Struct. Geol. 21, No. 4, 379-386.

Zuo, L. \& Baudet, B. A. (2015). Determination of the transitional fines content of sand-non plastic fines mixtures. Soils Found. 55, No. 1, 213-219. 